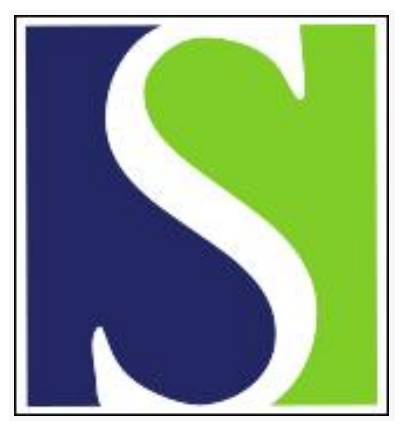

Scand J Work Environ Health 2003;29(4):288-296

https://doi.org/10.5271/sjweh.733

Issue date: Aug 2003

\title{
Prevention of farm injuries in Denmark
}

by Rasmussen K, Carstensen O, Lauritsen JM, Glasscock DJ, Hansen ON, Jensen UF

Affiliation: Department of Occupational Medicine, Herning Hospital, DK-7400 Herning, Denmark. heckra@rngamt.dk

The following articles refer to this text: 2008;34(5):327-336;

2012;38(3):193-208; 2014;40(6):649-653; 2015;41(5):478-485

Key terms: accident; agriculture; Denmark; farm injury; intervention; postmeasurement; premeasurement; prevention; randomized controlled trial

This article in PubMed: www.ncbi.nlm.nih.gov/pubmed/12934722

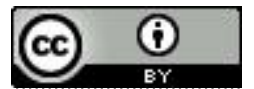




\title{
Prevention of farm injuries in Denmark
}

\author{
by Kurt Rasmussen, MD, ${ }^{1}$ Ce Carstensen, MD, ${ }^{1}$ Jens M Lauritsen, MD, ${ }^{2}$ David J Gasscock, MSc, ${ }^{1}$ \\ Oe N Hansen, MSc, ${ }^{1}$ Ulla F Jensen, MSc ${ }^{1}$
}

\author{
Rasmussen K, Carstensen O, Lauritsen JM, Gasscock DJ, Hansen ON, Jensen UF. Prevention of farm injuries in \\ Denmark. Scand J Work Environ Health 2003;29(4):288-296.
}

\begin{abstract}
Objectives This study examined the effects of a 4-year randomized intervention program that combined a safety audit with safety behavior training in the prevention of farm injuries.

Methods From a random sample of farms in the county of Ringkoebing, Denmark, 393 farms with 1597 residents and employees participated in a weekly self-registration of work-related accidents and injuries during 1 year. Worktasks and time at risk were recorded. A questionnaire including items on safety behavior was also mailed to each farm. Thereafter, the farms were randomly assigned to an intervention or control group.

Two hundred and one farms with 990 persons at risk participated in the intervention study. The main outcome measures were the number and severity of accidents, safety behavior, and farmsite safety audits.

Results Pre- and postmeasurements showed a substantial reduction in injury rates in the intervention group in comparison with a slight reduction in the control group. In a multivariate regression analysis the intervention effect was estimated to be a $30 \%$ injury-rate reduction of all injuries, while there was a $42 \%$ reduction for medically treated injuries only. Although none of these effects are statistically significant with the present sample size, their magnitude and direction support an intervention effect. The measures of safety behavior revealed significant improvements, and this finding supports the conclusion that the intervention effect was positive, since they concern some of the mediating factors on the pathway from intervention to improved injury rates.

Conclusions This intervention, which focused on safety behavior and was performed as a randomized controlled trial, was followed by a substantial reduction in the number of farm injuries. The reduction was particularly marked for the more severe injuries demanding medical treatment.
\end{abstract}

Key terms accident, agriculture, farm, injury, intervention, prevention, pre- and postmeasurements, randomized controlled trial.

In industrialized countries, agriculture ranks among the most hazardous work activities. In Denmark, farming is the occupation with the highest incidence of fatal work injuries. The yearly incidence per 100000 employed is four times greater in farming than in other occupations grouped together $(1,2)$. In 1999, farmers constituted only $3.2 \%$ of the Danish workforce, yet $25 \%$ of all fatal occupational injuries occurred in the agricultural sector. During the last 15-20 years, neighboring countries such as Sweden, Finland, and Holland have reduced the number of fatal and other work injuries by $30-50 \%$ (3). In comparison, Danish accident and injury figures have stagnated.
Most studies of farm injuries are restricted to matters concerning the measurement of incidence (4-8). The few reported attempts at injury prevention have been typically based on information campaigns (9). Effect evaluation is scarce. More-sophisticated designs have presumably been hindered by the logistical difficulties involved in conducting studies with the many, geographically dispersed units of analysis encountered in farming.

Our paper concerns the final phase (phase 3) of a series of studies under the heading "The West-Jutland Study on the Prevention of Farm Accidents": phase 1 being the registration and interview of all work-related

1 Department of Occupational Medicine, Herning Hospital, Herning, Denmark.

2 Accident Analysis Group, Odense University Hospital, Odense C, Denmark.

Reprint requests to: Dr Kurt Rasmussen, Department of Occupational Medicine, Herning Hospital, DK-7400 Herning, Denmark. [E-mail: heckra@ ringamt.dk] 
farm accidents resulting in hospital treatment during 1 year (January to December 1992) $(1,10)$; phase 2 comprising weekly farm-level registration of accidents in a randomly selected, representative sample of 393 farms (July 1993 to July 1994) (2); and phase 3 consisting of an evaluated intervention study designed as a randomized experiment within the sample of farms used in phase 2 (November 1995 to July 1997) (11). The aim of this phase was to examine the effect of intervention directed towards improving safety behavior among farm workers on work accidents and injuries.

\section{Subjects and methods}

\section{Study sample}

The county of Ringkoebing is a rural area of western Jutland. Farms are typically family units with one or a few farm laborers and with farm types fairly evenly distributed between dairy farms, swine producers, crop production only, and mixed production.

Phase 1 was a hospital-based study of more severe casualties referred to five emergency care units during 1 year (1) (table 1). The phase 2 sample, which formed the basis of this study, was drawn from the membership files of local farming organizations (accounting for $95 \%$ of all farms in the region). From a random sample of 794 farms (10\% of all farms in Ringkoebing county), 133 farms were excluded due to a cessation of farming activity. Agreement to participate in a year-long weekly self-registration of farm accident events was obtained from 393 farms. The 268 farms that refused participation were reached by telephone. The most common reason for not participating was "participation irrelevant because of atypical farm type". Nonparticipating farms were characterized as being part-time and as having older owners.

During phase 2, 16 farms dropped out, leaving 377 farms at the end this phase. Between phase 2 and the start of phase 3, 63 farms were excluded because of major changes on the farm. A further 106 farms chose not to participate beyond phase 2 (2).

The dropout farms were characterized by younger farmers with significantly fewer reported injuries in phase 2 (2). In all other respects they were comparable with the farms participating in phase 3 .

\section{Design}

The study design and time schedule is illustrated in figure 1 , showing the longitudinal approach of the 4 years of this randomized trial.

The intervention study sample consisted of the phase 2 farms that were still actively engaged in farming and willing to participate in this final phase, 16 months after the first registration period.

The remaining 208 farms were randomly assigned to an intervention group and a control group. Prior to randomization, the total study group was invited to meetings in which information on results from the registration phase and the procedure for the forthcoming intervention was presented. The participants were instructed to undertake accident registration as thoroughly as possible, no matter which group they were allocated into by the randomization, and to use the same guidelines as prior to the intervention period. Thereafter computer-generated randomization was performed, and information on the group allocation was sent by mail to the participants.

Between the start of phase 3 and the actual implementation of the intervention, additional changes to farm structure, a change of ownership, or health problems led to the loss of five farms from the trial group and two farms from the control group. Thus the intervention group contained 99 farms, and the control group had 102 farms. The unit of randomization was the farm, which contained a range of working people (the owner, farm laborers and family members participating in farm work more than 1 hour/week). If the focus had been on individual persons, this approach would be termed cluster randomization. Our unit of analysis in this phase of the study was the farm, for which workers' individual risk time, accumulated per farm, was used as the denominator in the calculation of injury rates. Most of the analyses presented in this report were based on data aggregated within the intervention and control groups, before versus after intervention.

Table 2 shows that the randomization was successful with respect to demographic and general farm characteristics. However, later analyses of phase 2 data

Table 1. Number of farms or farmers during different phases of the study.

\begin{tabular}{|c|c|c|}
\hline & $\mathrm{N}$ & Comment \\
\hline \multirow[t]{4}{*}{ Phase 1} & 8370 & $\begin{array}{l}\text { Al farmers in the county-hospital based emergency } \\
\text { care unit attendance of farm injuries }\end{array}$ \\
\hline & 794 & Random sample of farms \\
\hline & 133 & $\begin{array}{l}\text { Nonactive farms (passive members of the } \\
\text { farmers union }\end{array}$ \\
\hline & 268 & Not willing to participate \\
\hline \multirow[t]{7}{*}{ Phase 2} & 393 & Participants in the pre-intervention study \\
\hline & 16 & Dropouts during phase 2 \\
\hline & 63 & Excluded due to cessation of farm activity \\
\hline & 106 & Not willing to participate \\
\hline & 208 & Farms for randomization \\
\hline & 5 & $\begin{array}{l}\text { Dropouts in the intervention group during the } \\
\text { intervention }\end{array}$ \\
\hline & 2 & Dropouts in the control group during the study \\
\hline \multirow[t]{2}{*}{ Phase 3} & 99 & Participants in the intervention group \\
\hline & 102 & Participants in the control group \\
\hline
\end{tabular}




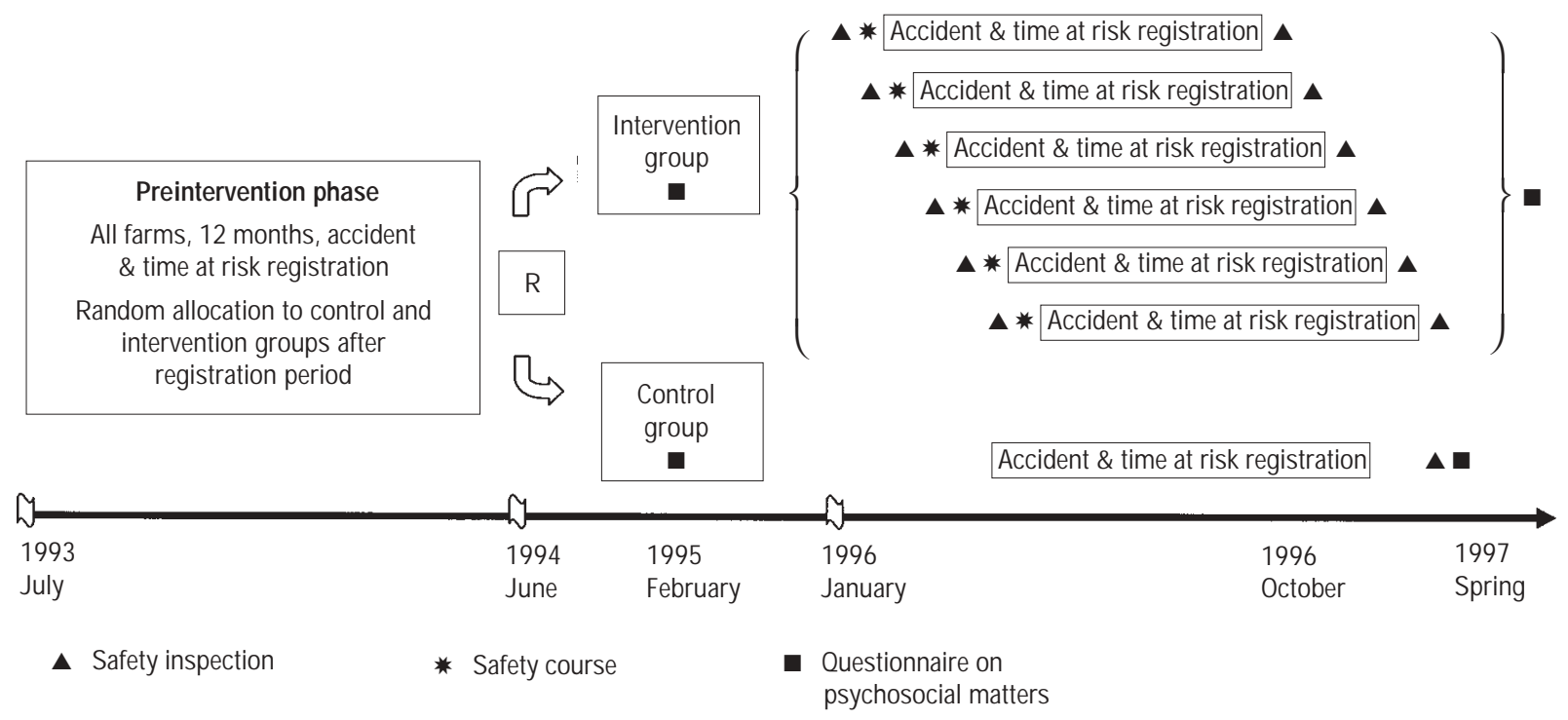

Figure 1. Eements of the design and schedule of the study. Baseline performed for 393 farms (1597 persons) prior to randomization into the control or intervention group. Subjects who agreed to continue werethen randomized to an intervention group (99 farms, 498 persons) and a control group (102 farms, 492 persons). Theintervention group was divided into smaller groups for thesafety course. Comparison by season was doneaccording to the same season for both the pre and postintervention.

Table 2. Distribution of the demographic variables after the randomization.

\begin{tabular}{|c|c|c|c|c|}
\hline \multirow[t]{2}{*}{ Variable } & \multicolumn{2}{|c|}{$\begin{array}{l}\text { Intervention group } \\
(\mathrm{N}=498)\end{array}$} & \multicolumn{2}{|c|}{$\begin{array}{l}\text { Control group a } \\
(\mathrm{N}=492)\end{array}$} \\
\hline & $\mathrm{N}$ & $\%$ & $\mathrm{~N}$ & $\%$ \\
\hline \multicolumn{5}{|l|}{ Gender } \\
\hline Male & 316 & 60.5 & 297 & 59.4 \\
\hline Female & 182 & 39.5 & 195 & 40.6 \\
\hline \multicolumn{5}{|l|}{ Affilliation } \\
\hline Owner & 99 & 20.5 & 102 & 20.7 \\
\hline Farm laborer & 91 & 18.3 & 88 & 17.9 \\
\hline Spouse & 91 & 18.5 & 99 & 20.1 \\
\hline Child & 157 & 31.5 & 142 & 28.9 \\
\hline Miscellaneous (temporary workers) & 60 & 12.0 & 61 & 12.4 \\
\hline \multicolumn{5}{|l|}{ Farm type } \\
\hline Dairy & 29 & 29.3 & 27 & 26.5 \\
\hline Swine & 37 & 37.4 & 39 & 38.2 \\
\hline Crop & 17 & 17.2 & 18 & 17.6 \\
\hline Mixed & 16 & 16.2 & 18 & 17.6 \\
\hline All & 99 & 49.3 & 102 & 50.7 \\
\hline \multicolumn{5}{|l|}{ Farm size index } \\
\hline Full-time work & 71 & 71.7 & 73 & 71.6 \\
\hline Part-time work & 20 & 20.2 & 21 & 20.5 \\
\hline Hobby & 8 & 9 & 8 & 8 \\
\hline
\end{tabular}

a Mean age 34.7 years for the intervention group and 36.8 years for the control group.

revealed differences between the two groups in terms of work-specific time at risk (table 3). More time was spent on machinery-related tasks and repair work in the intervention group. In agreement with this result, we found more injuries related to machinery and repair work in the intervention group prior to the intervention
Table 3. Distribution of the risk time (workhours/year) and injuries in the randomized study groups before the intervention (total workhours across farms).

\begin{tabular}{lrr}
\hline & $\begin{array}{l}\text { Intervention } \\
\text { group }\end{array}$ & \multicolumn{1}{c}{$\begin{array}{c}\text { Control } \\
\text { group }\end{array}$} \\
\hline Worktask & & \\
Animal-related & 213035 & 214311 \\
Machine-related & 87560 & 79453 \\
$\quad$ Repair- or maintenance-related & 23824 & 18494 \\
Total risk time during 1 year by worktask & 328998 & 316823 \\
Total risk time by mean weekly workhours & 466285 & 468908 \\
Risk one-half unadjusted a & 233143 & 234454 \\
Risk one-half adjusted a & 237597 & 228573 \\
Injuries/year & & \\
All injuries & 144 & 119 \\
$\quad$ Animal-related & 75 & 69 \\
$\quad$ Machine-related & 28 & 15 \\
$\quad$ Repair-related & 38 & 32 \\
$\quad$ Other & 3 & 3 \\
Medically treated & 36 & 35 \\
\hline
\end{tabular}

${ }^{a}$ Risk one-half (total risk time by weekly workhours): unadjusted $=\sim$ total risk time/2 season; adjusted $=\sim$ risk time for half a year, season adjusted by the included weeks over the year.

in comparison with the injuries experienced in the control group.

Preintervention injury registration took place over 1 year for the entire sample. Postintervention injury registration was carried out for 6-months for both the intervention and control groups. For all the farms in the 
control group, this procedure was carried out during the same 6-month period. For the intervention group, postintervention injury registration commenced upon completion of the intervention. Since it took approximately 3 months to conduct the intervention with farms in the intervention group, the 6-month period of accident registration did not commence simultaneously for farms in this group, but instead stretched over three-fourths of a year. This procedure introduced a seasonal bias to time at risk. To adjust for this bias, we calculated "risk onehalf adjusted", shown in table 3. For example, for farms undergoing postintervention injury registration during the autumn period, mean workhours per week was corrected by adding $30 \%$. This figure of $30 \%$ was based on data from phase 2 , showing that farmers in this sample worked $30 \%$ more hours during the autumn season than the yearly mean. When making pre- versus postintervention comparisons of injuries, we counted injuries in exactly the same weeks for both periods of registration in the intervention and the control groups. The time bars in figure 1 illustrate this approach.

\section{Intervention}

The intervention comprised a farm safety check, taking approximately one-half a day, and a 1-day safety course (11).

A farm safety specialist conducted a safety check of every farm in the intervention group. Altogether, 71 work routines (feeding, milking, harvesting, etc) were controlled with respect to the safety standards of hardware and the self-reported safety behavior employed by the farmer in carrying out specified tasks. Both hardware and behavior were scored on a 4-point scale ( $1=$ very good, $2=$ good, $3=$ poor, $4=$ =irresponsible). The farmer participated in this safety walk-through and received immediate verbal feedback about problems, risks, and hazards, as well as advice about how identified problems could be rectified. The farmer also received a written report containing recommendations about immediate and long-term improvements. Ninety-eight of the ninety-nine farms in the intervention group were visited.

Shortly after the safety check (typically within 1-4 weeks), all the adults who worked on the farm took part in a 1-day course conducted by occupational health physicians and psychologists. Courses were run for groups of $10-15$ people from approximately 5-6 farms at a time.

The safety course contained five elements. First, information was distributed about risk factors, with emphasis on concrete examples of preventable measures. Data obtained during the first accident registration phase was used, making the information particularly salient for the participants. Second, focus group discussions, moderated by two psychologists, were held in which the farmers themselves were the active participants. The farmers spoke about their own accidents, why accidents occurred, and what could have been done to prevent them, and they also discussed reasons and motives for unsate behavior and obstacles to safe behavior. The farmers acted as their own experts in that ideas and successful solutions were disseminated throughout the group. Third, direct confrontation was arranged with a seriously injured farmer who talked graphically about his accident experience and its consequences. The aim was to build upon increased knowledge and motivation by intensifying the emotional salience of farm accidents. Fourth, personal protective equipment was demonstrated. Finally, group discussions were arranged to facilitate concrete recommendations and improvements at the farm. Each farmer wrote a plan of action, listing changes that he was committed to make.

Farmers, farm laborers, and spouses from 89 of the 99 farms participated. The remaining 10 farms were sent a video and written material based on the course content and encouraged to use this material as the basis for discussions on the farm.

The intervention was based on theoretical and empirical work on behavioral change, as well as on participatory action research (12). The first part of the intervention contained a prescriptive safety survey of the farm, used as a "safety starting point". During the walk-through of the farm facilities, the safety engineer and the farmer discussed "good standards and practices" and the subsequent report to the farmer included points for immediate and long-term improvements. During this dialogue the catalytic process was initiated. The second part, the 1-day safety course, also included prescriptive elements (eg, farmers could inform each other of their own successful safety solutions during group discussions), while the catalytic process of increasing motivation to act was furthered by making risks emotionally salient and getting farmers to commit themselves, in the presence of their peers, to making specified changes.

\section{Effect measurement}

Accident and injury registration. After the end of the intervention, the farms in both groups completed an additional 6-months of accident registration (one registration form per week). The total response rate was $94 \%$.

Telephone interviews were conducted with all accident victims 2-3 months after the occurrence of the reported accidents. The interview concerned details of the work situation before and during the accident, as well as its health-related consequences. The registration and interview procedures were identical in the pre- and postintervention periods. 
On the basis of these interviews, accidents were classified as work-related versus nonwork-related. Incidents were further classified as accidents resulting in an injury that received professional treatment and accidents resulting in an injury requiring a break from work of less than or, respectively, more than 10 minutes (but no professional treatment). Minor scrapes and bruises that did not give rise to breaks in the work and self-treatment of the injury were not recorded. Critical incidents leading to "mechanical damage only" (eg, damage to a wall after contact with a tractor) or "near misses" were also recorded, but these data are not reported in this paper.

The inclusion criterion throughout both the second and third phases was "a sudden, unintended incident that occurs during the performance or supervision of farm work, and results in personal injury". Reported incidents that involved illness, acute strain injuries, and leisure activity accidents were excluded.

Farm safety visit. Following the second period of accident registration and approximately 9 months after the completion of the intervention, the farm safety check was repeated in the intervention group for the purpose of before-after comparisons. Ninety-four of ninety-nine farms received this second safety check. Nonintervention farms were also visited after 6 months of accident registration, and identical safety checks were made. In the control group, 84 of the 102 farms were visited. Failure to complete safety visits on all farms was due to practical problems that prevented arrangements being made for the visit.

Questionnaire. A questionnaire containing items on psychosocial variables was mailed to the principal farm operator of each farm, both 1 year before and 6 months after the intervention. The response rate was $85 \%$. The reduced number of farmers included in these analyses was due to missing values on items included in the scales. The questionnaire focused on safety attitudes and behavior, personality traits, and stress perceptions and symptoms. In this report, only data concerning safety behavior and the use of personal protective equipment have been used.

Two questionnaire scales were employed for the purpose of before-after comparison. The first of these contained 12 items and concerned "active" safety behavior (eg, "Do you regularly check that power takeoff shields are in order?"). Each item was scored on a 4point scale ranging from $1=$ always to $4=$ no. Item scores were summed, giving a possible total score of 12 to 48 . Higher scores represented poorer safety habits. The second scale contained six items on "passive" safety habits, namely, use of personal protective equipment (PPE use) (eg, "Do you use protective glasses when there is a risk of eye injury, eg, when using an angle grinder"?). The response categories and scoring were the same as with the previous scale. In this case the possible range for the total score was from 6 to 24, again with higher scores representing poorer safety habits. Scale items were chosen on the basis of the farm accident literature, consultation with farm safety experts, and pilot interviews with farmers. Behavior was included in these scales if it was considered important for safety, if farmers appeared to neglect it, and if it was to be focused on in the intervention. The Cronbach alpha coefficient for the "active" safety behavior scale was 0.59 , and for the "passive" safety behavior scale it was 0.60 . The reduced number of farmers included in the analyses involving these two scales was due to missing values on items included in the scales.

\section{Workhours and work routines}

During phase 2, all the farms registered the number of hours spent performing specified tasks involved in their daily and weekly routines within the following three general areas: work with animals, field work with machinery, and maintenance or repair work.

Task-specific time at risk was actively measured during the 1-year preintervention phase, which was used for task-specific risk calculations, published separately (2). Postintervention, the farmers were told to report changes to these previously given task-specific hours. However, since total weekly workhours could only be subdivided into specific tasks for $67 \%$ of the time, we chose "total weekly workhours" as the most suitable time-at-risk measure for this presentation.

\section{Statistical analysis}

Data analysis was performed using Epi-Info (version 5, CDC, Atlanta, GA, USA), SPSS (version 7.5, SPSS Inc, Chicago, IL, USA), and SAS (version 8.2, SAS Institute, Cary, NC, USA). Confidence intervals were calculated for accident rates using the Poisson distribution. A multiplicative model including five parameters was used to measure the effect of the intervention using Poisson regression analysis (SAS). Before-after comparisons of the questionnaire results employed methods of paired comparisons in the intermediate steps and an unpaired two-sample test for the final comparison between the intervention group and the control group.

\section{Results}

The results from questionnaire-based scores on the two scales of farm safety habits are depicted in table 4 , based 
Table 4. Results from the questionnaire-based scores on the two scales used for farm safety behavior. (PPE = personal protective equipment, $95 \% \mathrm{Cl}=95 \%$ confidence interval)

\begin{tabular}{|c|c|c|c|c|c|}
\hline \multirow[t]{2}{*}{ Safety behavior a } & \multicolumn{2}{|c|}{ Mean safety score } & \multirow[t]{2}{*}{ Mean of the differences ${ }^{b}$} & \multicolumn{2}{|c|}{ Intervention effect } \\
\hline & Preintervention & Postintervention & & P-value & $95 \% \mathrm{Cl}$ \\
\hline \multicolumn{6}{|l|}{ Active } \\
\hline Intervention group & $\begin{array}{l}25.92 \\
24.72\end{array}$ & $\begin{array}{l}24.40 \\
24.79\end{array}$ & -1.52 & . & . \\
\hline Intervention effect & . & . & -1.59 & 0.035 & $-3.08--0.11$ \\
\hline \multicolumn{6}{|l|}{ PPE use } \\
\hline $\begin{array}{l}\text { Intervention group } \\
\text { Control group }\end{array}$ & $\begin{array}{l}18.24 \\
18.17\end{array}$ & $\begin{array}{l}16.36 \\
17.75\end{array}$ & $\begin{array}{l}-1.88 \\
-0.42\end{array}$ & . & : \\
\hline Intervention effect & . & . & -1.46 & 0.005 & $-2.47--0.45$ \\
\hline
\end{tabular}

a For both the safety behavior index and the PPE use index, higher scores represent poorer safety habits.

b Postintervention - preintervention.

Table 5. Safety scores rated during the farm visit—differences between selected pre and postintervention work routines for the intervention group and the score from a single visit to a control farm (t-test for repeated measures). ${ }^{a}(95 \% \mathrm{Cl}=95 \%$ confidence interval)

\begin{tabular}{|c|c|c|c|c|c|}
\hline \multirow[t]{2}{*}{ Work routine } & \multicolumn{2}{|c|}{ Mean safety score } & \multirow[t]{2}{*}{ Mean of the differences ${ }^{b}$} & \multirow[t]{2}{*}{$95 \% \mathrm{Cl}$} & \multirow[t]{2}{*}{ P-value } \\
\hline & Preintervention & Postintervention & & & \\
\hline \multicolumn{6}{|l|}{ Working on ladders } \\
\hline $\begin{array}{l}\text { Intervention group } \\
\text { Control group }\end{array}$ & 2.13 & $\begin{array}{l}1.96 \\
2.13\end{array}$ & 0.17 & $0.05-0.29$ & 0.008 \\
\hline \multicolumn{6}{|l|}{ Repairing machinery } \\
\hline $\begin{array}{l}\text { Intervention group } \\
\text { Control group }\end{array}$ & 2.09 & $\begin{array}{l}1.82 \\
2.20\end{array}$ & 0.27 & $0.05-0.49$ & 0.015 \\
\hline \multicolumn{6}{|c|}{ Ceaning procedures (use of chemicals) } \\
\hline $\begin{array}{l}\text { Intervention group } \\
\text { Control group }\end{array}$ & 2.08 & $\begin{array}{l}1.97 \\
2.00\end{array}$ & 0.11 & $\begin{array}{c}0.01-0.21 \\
.\end{array}$ & 0.035 \\
\hline
\end{tabular}

a The safety standard of hardware and safety behavior were scored separately for 71 work routines on a 4-point scale $(1=$ very good, 2 = good, $3=$ poor, 4 = irresponsible). Because of no preintervention farm visit to control farms, the intervention effect could not be calculated as in table 4 .

b Postintervention - preintervention.

on individual answers from the principal farm operator. To compare the pre-post differences between the intervention and the control groups, we estimated the groupspecific pre-post differences in the scores, including their variances, using the methods of paired comparisons, and then compared these differences using an unpaired two-sample test. For both outcomes, the $95 \%$ confidence intervals $(95 \% \mathrm{CI})$ were below zero (P-values were $<0.05)$, and we concluded that there was an intervention effect for both of these measures.

The safety specialist's scored observations of safety standards in the intervention group prior to the intervention did not differ from those of the control group. When the safety scores before and after the intervention were compared for the intervention group, there was an improvement in the mean score for 31 of the 71 routines, and for 3 of the routines there was a decline in the safety standard with a significantly higher (poorer) score after the intervention. Table 5 illustrates selected aspects of the improvements in farmers' behavior, scored with respect to safety during farm inspections. The use of personal protective equipment had particularly improved, and this finding supports the questionnaire results (table 4). For certain safety measures, particularly substantial improvements were seen (eg, a fivefold increase in the prevalence of farmers wearing safety boots when working with animals in the stable).

Table 6 gives the basic figures concerning occurrences of injuries and the corresponding calculated injury rates. The injury figures for the 12-month preintervention period of accident registration are displayed in the first column of table 6 . In order to make pre- versus postinjury figures comparable, we counted injuries in exactly the same weeks of registration during the two periods, 6 months for each (columns 2 and 3 in table 6). As time at risk depended on season, we attempted season-adjusted times ("risk one-half adjusted" in table 3) when calculating adjusted injury rates; see the lower part of table 6. Season adjustment gave only slight changes in the injury rates and also in the preliminary calculations reported in columns 4 and 5 of table 6 , showing two descriptive pre-post measures. 
Table 6. Injury number and rate ${ }^{a}$ for the pre and postintervention periods of each group. ( $95 \% \mathrm{Cl}=95 \%$ confidence interval)

\begin{tabular}{|c|c|c|c|c|c|c|c|c|c|c|}
\hline & \multicolumn{4}{|c|}{ Preintervention injuries } & \multirow{2}{*}{\multicolumn{2}{|c|}{$\frac{\text { Postintervention injuries }}{1 / 2 \text { year }}$}} & \multicolumn{2}{|c|}{ Difference } & \multirow[t]{3}{*}{ Postrate/prerate } & \multirow[t]{3}{*}{$95 \% \mathrm{Cl}$} \\
\hline & \multicolumn{2}{|c|}{1 year } & \multicolumn{2}{|c|}{$1 / 2$ year $^{b}$} & & & \multirow{2}{*}{\multicolumn{2}{|c|}{$\begin{array}{c}\text { Rate Reduction } \\
(\%)\end{array}$}} & & \\
\hline & $\mathrm{N}$ & Rate & $\mathrm{N}$ & Rate & $\mathrm{N}$ & Rate & & & & \\
\hline \multicolumn{11}{|l|}{$\begin{array}{l}\text { Unadjusted values }{ }^{b} \\
\text { Intervention group }\end{array}$} \\
\hline $\begin{array}{l}\text { All injuries } \\
\text { Medically treated injuries }\end{array}$ & $\begin{array}{r}144 \\
36\end{array}$ & $\begin{array}{r}30.9 \\
7.7\end{array}$ & $\begin{array}{l}78 \\
22\end{array}$ & $\begin{array}{r}33.5 \\
9.4\end{array}$ & $\begin{array}{l}40 \\
12\end{array}$ & $\begin{array}{r}17.5 \\
5.1\end{array}$ & $\begin{array}{r}16.0 \\
4.3\end{array}$ & $\begin{array}{l}47.8 \\
45.8\end{array}$ & $\begin{array}{l}0.51 \\
0.54\end{array}$ & $\begin{array}{l}0.34-0.76 \\
0.25-1.15\end{array}$ \\
\hline \multicolumn{11}{|l|}{ Control group } \\
\hline $\begin{array}{l}\text { All injuries } \\
\text { Medically treated injuries }\end{array}$ & $\begin{array}{r}119 \\
33\end{array}$ & $\begin{array}{r}25.4 \\
7.0\end{array}$ & $\begin{array}{l}57 \\
18\end{array}$ & $\begin{array}{r}24.3 \\
7.7\end{array}$ & $\begin{array}{l}42 \\
17\end{array}$ & $\begin{array}{r}17.9 \\
7.3\end{array}$ & $\begin{array}{l}6.4 \\
0.4\end{array}$ & $\begin{array}{r}26.3 \\
5.2\end{array}$ & $\begin{array}{l}0.74 \\
0.95\end{array}$ & $\begin{array}{l}0.48-1.11 \\
0.46-1.94\end{array}$ \\
\hline \multicolumn{11}{|l|}{ Adjusted values ${ }^{c}$} \\
\hline $\begin{array}{l}\text { Intervention group } \\
\text { All injuries }\end{array}$ & 144 & 30.9 & 78 & 32.8 & 40 & 16.8 & 16.0 & 48.7 & 0.51 & $0.35-0.75$ \\
\hline Medically treated injuries & 36 & 7.7 & 22 & 9.3 & 12 & 5.1 & 4.2 & 45.5 & 0.55 & $0.27-1.10$ \\
\hline \multicolumn{11}{|l|}{ Control group } \\
\hline $\begin{array}{l}\text { All injuries } \\
\text { Medically treated iniuries }\end{array}$ & $\begin{array}{r}119 \\
33\end{array}$ & $\begin{array}{r}25.4 \\
7.0\end{array}$ & $\begin{array}{l}57 \\
18\end{array}$ & $\begin{array}{r}24.9 \\
79\end{array}$ & $\begin{array}{l}42 \\
17\end{array}$ & $\begin{array}{r}18.4 \\
7.4\end{array}$ & $\begin{array}{l}6.6 \\
0.4\end{array}$ & $\begin{array}{r}26.3 \\
5.6\end{array}$ & $\begin{array}{l}0.74 \\
0.94\end{array}$ & $\begin{array}{l}0.49-1.10 \\
0.49-1.83\end{array}$ \\
\hline
\end{tabular}

a Rate: number of injuries per 100000 workhours.

${ }^{b}$ One-half year preintervention: injuries counted in the same weeks pre and postintervention.

c Risk time adjusted for seasonal variation.

Table 7. Effect of the intervention as measured by two multiplicative models (Poisson regression)—parameter estimates and the $95 \%$ confidence intervals $(95 \% \mathrm{Cl})$ for the parameters.

\begin{tabular}{|c|c|c|c|c|c|c|}
\hline \multirow[b]{3}{*}{ Parameter } & \multicolumn{4}{|c|}{ Model 1: no common parameters between injury type } & \multirow{2}{*}{\multicolumn{2}{|c|}{$\begin{array}{c}\text { Model 2: all parameters in common } \\
\text { All injuries }\end{array}$}} \\
\hline & \multicolumn{2}{|c|}{ Nonmedically treated injuries only } & \multicolumn{2}{|c|}{ Medically treated injuries only } & & \\
\hline & Estimate & $95 \% \mathrm{Cl}$ & Estimate & $95 \% \mathrm{Cl}$ & Estimate & $95 \% \mathrm{Cl}$ \\
\hline Intercept & 17.06 & $12.5-23.4$ & 7.87 & $5.0-12.5$ & 24.94 & $19.2-32.3$ \\
\hline Intervention/control group & 1.38 & $0.9-2.1$ & 1.18 & $0.6-2.2$ & 1.32 & $0.9-1.9$ \\
\hline Postintervention-preintervention & 0.64 & $0.4-1.1$ & 0.94 & $0.5-1.8$ & 0.74 & $0.5-1.1$ \\
\hline Intervention-nonintervention & 0.78 & $0.4-1.5$ & 0.58 & $0.2-1.5$ & 0.70 & $0.4-1.2$ \\
\hline Reduction in injury rate & $22 \%$ & $-53-60 \%$ & $42 \%$ & $-52-78 \%$ & $30 \%$ & $-21-60 \%$ \\
\hline Probability of medical treatment & & & & & $32 \%$ & $-26-38 \%$ \\
\hline
\end{tabular}

The reduction in injuries (table 6) was marked in the intervention group, with a $49 \%$ injury rate reduction in the intervention group compared with the $26 \%$ reduction in the control group. For injuries requiring professional medical care, there was a $46 \%$ reduction in the intervention group and a $6 \%$ reduction in the control group.

Table 7 reports the results from the model-based statistical analysis of the injury rates. For this analysis, we applied a multiplicative model (Poisson regression) with the factor of intervention-nonintervention (the intervention factor) being the parameter of interest and with the two factors of post-pre (the period factor) and intervention-control group (the group factor) acting as confounders. This model allowed us to disentangle the intervention effect from the disturbances rising from the two confounders. To obtain additional relevant estimates, we also included the relation between the rates for medically treated-nonmedically treated injuries in the model, on the assumption, in accordance with the result of a goodness-of-fit test, that this relation is the same in all situations. The parameter expresses the probability of an occurred injury being medically treated. The inclusion or exclusion of this element of injury severity in the model did not affect the estimates found for the other factors.

The main result of the analysis was that there is a considerable, though not statistically significant, intervention effect (preventive fraction), with a $30 \%$ reduction in the injury rate $(0.70,95 \% \mathrm{CI} 0.4-1.2)$ for all injuries and a $42 \%$ injury-rate reduction $(0.58,95 \% \mathrm{CI}$ $0.2-1.5)$ for the medically treated injuries only. 


\section{Discussion}

This study showed improvements in farmers' safety behavior, as well as in safety standards at farm locations, after an intervention program. These changes are considered to be logical and necessary conditions for attaining the ultimate goal: a reduction in accidents and injuries. After the intervention, injuries were reduced by $30-40 \%$, as demonstrated via a randomized-controlled trial design.

The greatest threat against the found injury reduction was information bias. The entity of injury registration was 201 different farm locations, the farmer himself being the primary data collector. Even after written and verbal instructions, registration practices may differ somewhat from person to person. It should be considered that the intervention group was in closest contact with the project group (1-day course plus half a day farm visit). The nature and direction of any registration bias that may have been introduced is not known, but one could argue that the intervention group, being more motivated and informed, would be keener event reporters. If so, then an underestimation of the true effects of the intervention could have occurred.

The preintervention excess of injuries in the intervention group (tables 3 and 7) was the concern of a thorough analysis, and it requires some comments. First, it was the most prominent for all injuries and only slightly apparent for medically treated injuries, the registration of which one would expect to be more reliable. Second, randomization was effective with regard to all important farm demographic variables (table 2). Of course, the possibility of heterogeneity between farms cannot be excluded (table 3 ).

The complex interplay of numerous environmental and individual risk factors that leads to accident occurrence precludes the establishment of totally identical experimental groups via randomization procedures. Our data did, however, allow us to identify the reason for the greater frequency of injuries in the intervention group. This excess of injuries was associated with accidents involving machinery and repair work, whereas there were no between-group differences with regard to injuries occurring during work with animals. This situation corresponded to a greater time at risk for precisely machine and repair work for the intervention group (table 3).

The other main problem of the study was related to the fact that the 6-month period of postintervention accident registration took place during different seasons in the two groups. Statistical adjustments for time at risk were not a completely satisfactory solution. Identical registration periods would have been preferable.

Randomized controlled trials are difficult to perform in work environment settings for a number of reasons, for example, all other exposures cannot be controlled and the intervention cannot be blinded as it can in clinical randomized-controlled trials at hospitals. Therefore, a study is more prone to a placebo effect (Hawthorne effect) for the control group, and statistically significant results of the intervention are difficult to achieve. Our finding of the biggest placebo effect for the less serious nonmedically treated injuries may speak in favor of this argument. From table 7, it appears that the relatively large period effect (post-pre), combined with a small intervention effect on the nonmedically treated injuries, as compared with the relatively small period effect and relatively large intervention effect on the medically treated injuries, may indicate that the placebo effect occurs mostly when the control group most easily can "produce" it.

The main methodological strength of the present study was the use of a randomized-control trial design using farms representative of the trade in a Danish setting, with approximately equal numbers of dairy, swine, crop, and mixed farms. This use strengthened the generalizability to the rest of the Danish farm population and, to some extent, to other countries with similar industrialized agricultural production. During the course of this study, we visited farms in various locations, including Sweden, the United States, and Australia. We found many similarities with Danish farms in terms of physical work conditions and farmers' safety attitudes.

An overrepresentation of younger farmers among the dropouts probably did not affect generalizability, as the injury rates and accident types were not related to younger age, according the total data material in previous parts of our "West-Jutland Study of the Prevention of Farm Accidents" (2). We found a change in age-related injury rates at the age of 50 years with a slightly reduced injury rate for those over 50 years of age.

Most previously published literature on farm injury prevention involves public information campaigns and cross-sectional effect evaluation (13-16). That approach has two fundamental flaws. The lack of before versus after measurements and the lack of suitable comparison or control groups. Furthermore, when the intervention under study consists of general safety information, an eventual effect is hard to differentiate from the effects of information from other sources that are usually present. This situation applies to most published farm safety programs of an educational or informational nature $(17,18)$. Few farm injury prevention studies address, as the present one, psychosocial and safety behavior matters (19-21).

In a Swedish study from 1992, 120 persons with mixed farm and forest work underwent a 2-day safety training course (22). Improved safety practices, as well 
as a decrease in the injury rate, was found for the before versus after measurements.

The "West-Jutland Study on the Prevention of Farm Accidents" has shown that preventive actions aimed at the problem of occupational farm injury are both possible and feasible. The two elements of the intervention employed in our study, a farm safety audit and a safety course, have now been made available to all Danish farmers via instructors educated by the Danish Farm Council and the research team behind the present project.

\section{Acknowledgments}

This study was supported by grants from The Danish Insurance Association, The Work Environment Fund, The Health Fund of the Danish Ministry of Health, and the Public Health Research Fund of the counties of Ribe and Ringkoebing, Denmark.

\section{References}

1. Carstensen O, Lauritsen J, Rasmussen K. The West-Jutland study on prevention of farm accidents, phase 1: a study of work specific factors in 257 hospital-treated agricultural injuries. J Agric Saf Health 1995;1:231-9.

2. Rasmussen K, Carstensen O, Lauritsen J. Incidence of unintentional injuries in farming based on one year of weekly registration in Danish farms. Am J Ind Med 2000;38:82-9.

3. Menckel E, Kullinger B. 15 years of research in occupational injuries in Sweden. Stockholm: Council for Research in Working Life; 1996.

4. Layde PM, Stueland DT, Nordstrom DL. Representativeness of trauma center registries for farm injury surveillance. Accid Anal Prev 1996;28:581-6.

5. Nordstrom DL, Layde PM, Olsen KA, Stueland O, Brandt L, Rollen MA. Incidence of farm-work-related acute injury in a defined population. Am J Ind Med 1995;28:551-64.

6. Zhou C, Roseman JM. Agricultural injuries among a population-based sample of farm operators in Alabama. Am J Ind
Med 1994;25:385-402

7. Pickett W, Brisson RJ, Niezgode H, Chipman ML. Non fatal farm injuries in Ontario: a population-based survey. Accid Anal Prev 1995;27:425-33.

8. Pratt D, Marvel L, Darrow D, Stallones L, May J, Jenkins P. The dangers of dairy farming: the injury experience of 600 workers followed for two years. Am J Ind Med 1992;21:63750.

9. Chapman LJ, Schuler RT, Wilkinson TL, Skjolass CV. Farmwork hazard prevention efforts by school-based agricultural education instructors. Am J Ind Med 1995;28:565-77

10. Hansen TB, Carstensen O. Hand injuries in agricultural accidents: J Hand Surgery 1999;24(2):190-2.

11. Glasscock D, Hansen ON, Rasmussen K, Carstensen O, Lauritsen J. The West Jutland study of farm accidents: a model for prevention. Saf Sci 1997;25:105-12.

12. Ajzen I, Fishbein M. Understandig attitudes and predicting social behavior. Englewood Cliffs (NJ): Prentice Hall; 1980.

13. Lundquist $\mathrm{P}$, Gustafson B. Accident and accident prevention in agriculture: a review of selected studies. Int J Ind Ergon 1992:10:311-9.

14. Brisson R, Pickett C. Nonfatal farm injuries on 117 eastern Ontario beef and dairy farms: a one-year study. Am J Ind Med 1992;21:623-36.

15. Thelin A. Agricultural occupational and environmental health policy strategies for the future. Am J Ind Med 1990; 18:523-6.

16. Rodriquez LA, Schwab CV, Peterson JN, Mille LJ. Safe farm: the impact of IOWA public information comparing. J Agric Saf Health 1997;3:109-23.

17. Shannon HS, Robson LS, Gaustello SJ. Methodological criteria for evaluating occupational safety intervention research. Saf Sci 1999;31:161-79.

18. Gaustello SJ. Do we really know how well our occupational accident prevention programs Work? Saf Sci 1993;16:445-63.

19. Glasscock DJ. Psycho social factors and occupational accidents in farming: an empirical study and literature review of accident theories and research with special attention to stress. Aarhus: Institute of Psychology, University of Aarhus; 1999.

20. Sulzer-Azaroff B. The modification of occupational safety behavior. J Occup Accid 1987;9:177-97.

21. Iverson RD, Erwin PJ. Predecting occupational injury: the role of affectivity. J Occup Organ Psychol 1997;70:113-28.

22. Jansson BR, Jacobsson BS. Medical consequences of workrelated accidents on 2454 Swedish farms. Scand J Work Environ Health 1988;14:21-6

Received for publication: 18 March 2002 